\title{
COMMENTARY
}

\section{Subjectivity can be inhumane}

Gavin Yamey, Deputy editor, wjm

West J Med 2000;173:143

In Carroll's postmodern world, proof is a lie, while intuition is an ally. Modernism and objectivity are inhumane, while subjectivity is the kinder, more gentle way to help the sick and suffering. And evidence-based medicine is not to be trusted. This way cruelty lies, for no amount of statistical analysis can prove how to provide compassionate care to each unique patient.

But the problem with making subjectivity our god is that it is sometimes wrong. Worse still, it is sometimes callous. Practices based on intuitive thinking have proven harmful. One example is the technique of performing episiotomies on women in labor. The rationale seemed kind: a clean cut is surely preferable to a spontaneous tear, and it is bound to protect the perineum and sphincters during childbirth. But the evidence tells a different story. Women who have episiotomies are at higher risk of fecal incontinence than those with spontaneous lacerations. ${ }^{1}$ Our instincts were wrong. Medicine must always evolve, continually integrating what is "known" into our daily working lives. We must be willing to let go of our previous truths, as new truths arise. Doctors are being unkind to their patients when they place their faith in instinct and tradition alone.

Evidence is only tyrannical when it is applied in a vacuum. The art of caring for the sick involves adapting the best available clinical evidence to the individual patient. Evidence-based medicine has the individual as its focus, emphasizing the "compassionate use of individual patients' predicaments, rights, and preferences in making clinical decisions about their care."2 This emphasis is not so far from postmodernism's view of a unique, lived experience. $^{3}$

Sometimes evidence is, of course, unnecessary. We don't need a randomized controlled trial to know it is valuable to hold the hand of the dying: patients tell us that they find it comforting, and we see how it eases their fear and isolation. There are many such values in health care that are based on justice and equanimity. The charity Age Concern has outlined 12 principles of "a good death." These include affording patients dignity, allowing them access to spiritual and emotional support, and ensuring that they are able to retain control over what remains of their lives. ${ }^{4}$ We don't need to prove the value of these just and ethically sound principles.

And sometimes, when we search for evidence, we find none of any worth. Many systematic reviews show that the original trials were of such poor quality that no useful conclusions can be drawn. Does this mean that we should abandon such literature reviews? I would argue not, for these unanswered questions can become a compassionate guide, telling us which areas of clinical medicine we have neglected in our research efforts.

Carroll reminds us how dangerous it can be to put our trust in evidence. He is right, of course, because there is no underlying, objective reality that can explain all of medicine's uncertainties. Proof is sometimes used in a vain attempt to capture and control knowledge. More worrying is the question of who "owns" the evidence, and whose interests does it promote? The pharmaceutical industry, for example, funds many of the highest profile trials, and it has attempted to suppress negative trial results. ${ }^{5}$ There is an ancient Arabic saying, which is: "Trust in God, but tie up your camel at night." We should use evidence to guide us in our clinical practice, but we must always be wary of its origins.

But if the truth about proof is really that there is none at all, then what should we tell our patients when they ask us which is the best treatment? We could answer them by quoting an early postmodernist, Benjamin Franklin, who said: "He's the best physician that knows the worthlessness of most medicines." 6 This therapeutic nihilism, however, would be an unkind lie. Evidence-based medicine is not perfect, but in giving patients the best available information about benefits and harms, it is the most humane we have to offer.

References

1 Signorello LB, Harlow BL, Chekos AK, Repke JT. Midline episiotomy and anal incontinence: retrospective cohort study. BMJ 2000;320:86-90.

2 Sackett DL, Rosenberg WMC, Muir Gray JA, et al. Evidence based medicine: what it is and what it isn't. BMJ 1996;312:71-72.

3 Chan JJ, Chan JE. Medicine for the millennium: the challenge of postmodernism. Med J Australia 2000;172:332-334.

4 Debate of the Age Health and Care Study Group. The Future of Health and Care of Older People: The Best is Yet to Come. London: Age Concern, 1999.

5 Yamey G. Scientists who do not publish trial results are "unethical." BMJ 1999;319:939.

6 Franklin B. Poor Richard, 1733. In: Labaree LW, ed. The Papers of Benjamin Franklin. Vol 1. January 1706 through December 1734. New Haven: Yale University Press, 1959:316. 